\title{
12 \\ NOTAS SOBRE O TECNICISMO EDUCACIONAL: FUNDAMENTOS E REFLEXÕES NO CONTEXTO BRASILEIRO*
}

\author{
Wilney Fernando Silva \\ Armindo Quillici Neto
}

\section{Introdução}

Ciência e técnicas de toda espécie, pela sua proliferação incontrolada, levam a descentrar ou a excentrar a realidade bumana.

(GUSDORF, 1978, p. 85)

Este capítulo tem como objetivo compreender o movimento tecnicista na educação brasileira, contornando suas características gerais e seus fundamentos para, a partir daí, observar as principais mudanças no fazer pedagógico e localizar o docente nesse paradigma. Utilizaremos, para a realização dessa tarefa, os conceitos teóricos de Dermeval Saviani, Acácia Zeneida Kuenzer, Lucília Regina S. Machado, José Carlos Souza Araújo, Ludwig Von Bertalanffy, Burrhus F. Skinner e Frederick W. Taylor.

Conforme Saviani (1999), ao findar a primeira metade do século XX, o escolanovismo, movimento de cunho liberal que significou a tentativa de renovação da escola pelos métodos, apresentava sinais visíveis de exaustão. As esperanças depositadas na reforma da escola foram frustradas e um sentimento de desilusão começava a se alastrar nos meios educacionais. Para Kuenzer e Machado (1982), no momento em que o "desenvolvimento e econômico com segurança" era o carro-chefe da ideologia do governo militar de 1964, a baixa produtividade, expressa por baixos índices de satisfação da demanda escolar em relação ao total da população e pelos altos índices de evasão e repetência, era apresentada como um dos entraves à conquista do tipo de educação almejada.

Segundo Araújo (2002), as várias teorizações ocorridas nos países tidos de primeiro mundo tornaram-se especulares às necessidades brasileiras. As próprias condições e os problemas postos pela instalação do desenvolvimento capitalista, em sua fase monopolista, também propiciaram a adoção de novas técnicas. A demanda de mão de obra representada pelas multinacionais trazia, em decorrência da transposição do modelo de produção, a importação do modelo de formação utilizado nos Estados Unidos. A opção pela tecnologia

*DOI - 10.29388/978-65-86678-49-9-0-f.197-214 
educacional $^{1}$ configurou-se, então, como a possibilidade de transpor, para o sistema de ensino, o modelo organizacional característico do sistema empresarial, visando à reordenação do sistema educacional com base nos princípios da racionalidade, eficiência e produtividade.

A partir da década de 1960, houve, assim, uma conjugação de teorias psicológicas, sistêmicas, de administração, de comunicação, como que amalgamando-se para servir de guia ao processo de modernização da sociedade brasileira. No dizer de Kuenzer e Machado (1982, p. 30), a partir daí, a “[...] febre sistêmica assolou o país [...]" e com ela as discussões sobre o Tecnicismo apontaram novos caminhos para a educação e para o fazer pedagógico.

Araújo traz o conceito de Tecnicismo pedagógico:

O Tecnicismo pedagógico significou sobrelevar as técnicas, os processos, os recursos materiais ligados à dinâmica concreta do ensinar e do aprender. Tal sobrelevação tende a enfatizar, quando não chega a radicalizar, a autonomia dos recursos técnicos. Em íntima conexão com essa maneira de pensar, a escola tende a ser concebida como autônoma em relação ao processo social, envolvida com as ideias de racionalização ${ }^{2}$, de eficiência e de eficácia que permearam todos os níveis do sistema de ensino (ARAÚJO, 2002, p. 15).

Metodologicamente, este capítulo será dividido em três partes. Inicialmente, discutiremos como se desenhou, de uma forma sintética, o Tecnicismo bem como seus fundamentos. Nesse momento, as categorias de racionalidade, produtividade, neutralidade e eficiência serão abordadas. $\mathrm{Na}$ segunda parte, apresentaremos como esse Tecnicismo, de ordem fabril, se apropria do espaço escolar e promove uma reordenação do processo educativo de maneira a tornálo objetivo e operacional. Será importante contextualizar a educação brasileira no período da ditadura militar de 1964 e as principais reformas concretizadas na época. A tecnologia educacional e a tecnoburocracia serão categorias animadas. Por fim, mostraremos as principais críticas ao Tecnicismo educacional. Essas críticas corroboram à quebra de paradigma confiável e, portanto, recomendável à prática docente. No entanto, levantaremos questões atuais e as problematiza-

\footnotetext{
${ }^{1}$ O termo tecnologia é conceituado por Abbagnano (2007) como o emprego de conhecimentos científicos na esfera da produção, transportes, das comunicações, dos serviços, da educação etc. caracterizada como a totalidade das técnicas dominadas por determinado grupo ou cultura.

${ }^{2}$ M. Weber introduziu a noção de Racionalidade enquanto conceito sociológico fundamental, concebendo-a como uma característica de determinado tipo de agir social. Nas ciências sociais (economia e teoria das decisões), a noção foi elaborada, com o auxílio de técnicas altamente formalizadas, em relação ao comportamento individual e coletivo e à escolha racional dos meios em vista de determinados fins. Sob o pano de fundo das discussões filosóficas modernas e contemporâneas emerge como tema dominante uma imagem da Racionalidade estreitamente entrelaçada ao mundo moderno e à civilização ocidental (ABBAGNANO, 2007).
} 
remos à luz da prática social para além da dimensão técnico-pedagógica, pois, como bem afirma Araújo (2002, p. 29), “[...] embora a prática docente tenha se tornado menos vulnerável com as promessas do Tecnicismo, parece um só tempo, tempo de Tecnicismo ainda a nos seduzir".

\section{Os fundamentos do Tecnicismo}

Os fundamentos do Tecnicismo remontam do final do século XIX e são ancorados na Teoria Geral da Administração, de Frederick Taylor e Henri Fayol; na Teoria Geral de Sistemas, de Von Bertalanffy; nas concepções de ensino ligadas à utilização de recursos audiovisuais, de James Finn; na Psicologia Comportamentalista de Educação, de B. F. Skinner; e na Filosofia Positivista, de Auguste Comte.

A Teoria Geral de Administração (TGA), segundo Kuenzer e Machado (1982), surge de forma sistematizada na final do século XIX, tendo como preocupação central o controle do processo produtivo, necessidade gerada pelo desenvolvimento capitalista que, introduzindo novas relações de produção a partir da compra e venda de força de trabalho, transfere o controle realizado internamente pelo produtor, a uma instância superior a ele, a da gerência.

Taylor (1976, p. 35) propõe cinco princípios para a TGA:

Substituir os métodos empíricos e improvisados por métodos científicos e testados (planejamento).

Selecionar os trabalhadores para suas melhores aptidões e treiná-los para cada cargo (seleção ou preparo).

Supervisionar se o trabalho está sendo executado como foi estabelecido (controle).

Disciplinar o trabalho (execução).

Trabalhador fazendo somente uma etapa do processo de montagem do produto (singularização das funções).

Desta forma, Taylor defende três pontos básicos: separação entre o planejamento do trabalho e a sua execução no processo total do trabalho, permitindo que os planejadores usem o monopólio do conhecimento para controlar cada fase do processo produtivo. A gerência, por sua vez, tem como função impor ao trabalhador a maneira de realizar a tarefa e controlar sua execução. E o treinamento do trabalhador para a execução otimista de sua tarefa específica propiciando o aumento de sua produtividade (TAYLOR, 1976). A TGA apregoou, portanto, uma racionalização ${ }^{3}$ do processo produtivo,

${ }^{3}$ A noção/conceito de Racionalidade vem com a noção entrelaçada com o mundo moderno, é elaborada com o auxílio de técnicas altamente formalizadas em relação ao comportamento individual e coletivo e à escolha racional dos meios em vista de determinados fins. É a 
por meio da fragmentação do trabalho, separando os que planejam e controlam dos que executam.

Mas será a partir da aplicação da Teoria Geral dos Sistemas (TGS) à organização do trabalho, do biólogo austríaco Ludwing Von Bertalanffy, publicada entre 1950 e 1968, que a racionalização e o controle com vistas à eficiência, chegam ao seu extremo. Para Kuenzer e Machado (1982), essa teoria configurou-se como uma abordagem mais sofisticada, embora sua matriz venha da filosofia taylorista.

Bertalanffy (1975) operacionaliza a TGS com os seguintes conceitos:

- Sistema: qualquer entidade composta de partes interrelacionadas, interdependentes, interatuantes, que têm um objetivo comum.

- Organização: relações entre as partes interdependentes que mantêm o sistema. Através delas as partes se influenciam reciprocamente mediante um processo de instrução e controle que objetiva a manutenção das outras partes e de si mesmas.

- Hierarquia: os elementos constituintes de determinado sistema podem considerar-se sistemas de ordem inferior (sistema maior e subsistemas).

- Sistemas abertos e fechados: apresentam ou não interfaces com o meio ambiente. Essa distinção permite a elaboração de uma taxionomia que parte das estruturas até chegar ao nível mais aberto que é o da organização social.

- Homeostase: é a estabilidade, entendida como equilíbrio dinâmico, que se constitui no ponto crucial da organização; só o que é estável pode ser descrito; todas as perturbações na estabilidade dão início a reações compensatórias, através de retroalimentação.

- Retroalimentação: qualquer meio pelo qual o produto de um processo é medido e conferido com um padrão preestabelecido, iniciando-se ação corretiva sempre que se constate desvio.

- Representação de sistemas através de modelos: são abstrações, representações simplificadas da realidade, construídas a partir de observações e mensurações; permitem experimentações, simulações e previsão. Uma ciência é tanto mais exata quanto maior for a correspondência entre os modelos e a realidade.

- Totalidade: o todo se sobrepõe às partes, que mantêm relações de causa e efeito entre si; as alterações nas partes causam alteração no todo; esse conceito repousa na ideia de homeostasia, de equilíbrio dinâmico; as partes se reajustam em busca da harmonia, o que leva o sistema a se desenvolver. Não há lugar para a contradição, o que faz esse conceito se

característica de determinado tipo de agir social. Assim, a Racionalidade (científica) é entendida como um conjunto de valores (cognitivos) proposto e pensado pela comunidade científica (ABBAGNANO, 2007). 
aproximar da concepção funcionalista de organização social (BERTALANFFY, 1975, p. 39).

O Tecnicismo também teve influências da Teoria Comportamentalista da Educação, de Burrhus F. Skinner, sobretudo por meio de seu livro intitulado “Tecnologia do Ensino", de 1972. Segundo Skinner (1972), a aprendizagem é uma aquisição de comportamentos mediante relações mais ou menos mecânicas entre um estímulo e uma resposta. Assim, em situações idênticas, esperam-se comportamentos idênticos.

Neste processo, o indivíduo é visto como ser passivo em todo o processo. A aprendizagem é sinônima de comportamento expresso e permite a modelagem do indivíduo. O reforço é um dos principais motores da aprendizagem. Autor das famosas máquinas de ensinar, Skinner expressa três vantagens fundamentais no uso dessa tecnologia:

1) Estímulo positivo entre pergunta e resposta: feedback imediato da máquina à resposta dada pelos alunos. 2) Ritmo de aprendizagem individual: os alunos não perdem tempo ao esperar a resolução de outros alunos. Cada um trabalha em seu ritmo eficiente. 3) Possuem um programa cuidadosamente planejado: do mais simples para o mais complexo, com pequenos passos a serem seguidos (SKINNER, 1972, p. 145).

A última influência do Tecnicismo vem da Filosofia Positivista. Herdeiro dessa filosofia, o Tecnicismo traz o entendimento da ciência concebida como neutra e objetiva. Emprega para isso o uso da tecnocracia pelos detentores de poder. Abbagnano (2007) define tecnocracia como o uso da técnica como instrumento de poder por parte de dirigentes econômicos, militares e políticos, para a defesa de seus interesses e controle da sociedade.

Conforme Severino (1986), o Positivismo tem como pressupostos: 1) o conhecimento científico é a única forma de conhecimento válido e objetivo; 2) uma teoria somente é correta se ela for comprovada por meio de métodos científicos válidos; 3) a objetividade da ciência basta para suspender a subjetividade do pesquisador; 4) o progresso da humanidade depende exclusivamente dos avanços científicos (SEVERINO, 1986).

\section{O Tecnicismo Educacional no contexto brasileiro}

Segundo Luckesi (2003), o Tecnicismo foi introduzido na educação brasileira na década de 1960, no decorrer do regime militar, através da implantação dos programas de desenvolvimento social e econômico "Aliança para o Progresso" e acordo "MEC-USAID”, frutos do convênio de cooperação 
firmado entre Brasil e Estados Unidos da América. A implantação do modelo tecnicista foi oficializada por meio da promulgação das Leis 5.540/68 e 5.692/71, que, respectivamente, reformulou a educação superior e instituiu o ensino de $1^{\circ}$ e $2^{\circ}$ graus.

Conforme estudos de Saviani (1999), a partir do pressuposto da neutralidade científica e, inspirado nos princípios de racionalidade, eficiência e produtividade dos sistemas apresentados anteriormente, o Tecnicismo vai advogar para a reordenação do processo educativo de maneira a torná-lo objetivo e operacional, de modo semelhante ao que ocorreu no trabalho fabril.

Com efeito, se no artesanato o trabalho era subjetivo, isto é, os instrumentos de trabalho eram dispostos em função do trabalhador e este dispunha deles segundo seus desígnios, na produção fabril essa relação é invertida. Aqui é o trabalhador que deve se adaptar ao processo de trabalho, já que este foi objetivado e organizado na forma parcelada. Nessas condições, o trabalhador ocupa seu posto na linha de montagem e executa determinada parcela do trabalho necessário para produzir determinados objetos. O produto é, pois, uma decorrência da forma como é organizado o processo (SAVIANI, 1999, p. 23).

O foco principal desta tendência pedagógica é produzir sujeitos capazes e eficientes para o desempenho de funções no mercado de trabalho. Ao valorizar as informações científicas, presentes nos manuais técnicos e de instrução, incumbe à escola divulgar o modelo de produção capitalista, de forma a que o aluno internalize e seja bem treinado para inserir-se profissionalmente no sistema econômico vigente (LUCKESI, 2003).

$\mathrm{Na}$ perspectiva da Pedagogia Tecnicista, buscou-se planejar a educação de modo a dotá-la de uma organização racional capaz de minimizar as interferências subjetivas que pudessem colocar em risco sua eficiência. Para tanto, era importante operacionalizar os objetivos e, pelo menos em certos aspectos, mecanizar o processo, afirma Saviani (1999).

Kuenzer e Machado (1982), asseguram que a Pedagogia Tecnicista significou a absorção, pela educação, da perspectiva empresarial. Nessa perspectiva, "[...] os dispêndios com a educação passam a ser justificados por motivos econômicos, considerando-a dotada de um valor econômico próprio, como um bem de produção (capital) e não apenas como um bem de consumo" (CANDIOTTO, 2002, p. 200).

Se na Pedagogia Tradicional a iniciativa cabia ao professor que era ao mesmo tempo o sujeito do processo, o elemento decisivo e decisório; na Pedagogia Nova a iniciativa desloca-se para o aluno, situando-se o nervo da ação educativa na relação professor-aluno, portanto, relação interpessoal, intersubjetiva. Mas é na Pedagogia Tecnicista que o elemento principal passa a 
ser a organização racional dos meios, ocupando professor e aluno posição secundária, relegados que são à condição de executores de um processo cuja concepção, planejamento, coordenação e controle ficam a cargo de especialistas supostamente habilitados, neutros, objetivos, imparciais, como esclarece Saviani (1999).

A escola atua, assim, no aperfeiçoamento da ordem social vigente (o sistema capitalista), articulando-se diretamente com o sistema produtivo; para tanto, emprega a ciência da mudança de comportamento, ou seja, a tecnologia comportamental. Seu interesse imediato é o de produzir indivíduos "competentes" para o mercado de trabalho, transmitindo, eficientemente, informações precisas, objetivas e rápidas (LUCKESI, 2003, p. 61).

A partir das influências sofridas por várias correntes e pensamentos, Saviani (2010) aponta três pressupostos principais da Pedagogia Tecnicista. O primeiro afirma que o ensino é um processo de comportamento através do uso de reforço das respostas que se quer obter; o bom ensino depende da organização e das condições estimuladoras de modo que o aluno saia da aprendizagem diferente de como entrou. $\mathrm{O}$ segundo pressuposto afirma que o objetivo educacional é o estudo científico do comportamento, das leis naturais e do controle objetivo das variáveis nas relações humanas. Por último, o terceiro aponta que os componentes da aprendizagem são: a motivação, a retenção e a transferência. Eles decorrem da aplicação do comportamento. O comportamento aprendido é uma resposta a estímulos externos, controlados por meios de reforços que ocorrem com a resposta ou após a mesma.

Como resultado dessas influências e processos, o Tecnicismo Pedagógico apresentou as seguintes propostas pedagógicas: o enfoque sistêmico, o microensino, o telensino, a instrução programada e as máquinas de ensinar que serão aqui descritas sinteticamente.

- Enfoque Sistêmico: orientação teórico-prática dos processos de interação e comunicação entre os componentes de um determinado sistema educacional. Nele, o mundo é visto como um todo, indiviso, fundindo-se todas as partes do universo (BERTALANFFY, 1975).

- Microensino: constitui uma experiência simplificada, uma microexperiência de ensino, que ao mesmo tempo providencia a teoria e a prática didáticas e possibilita a avaliação da competência específica por meio da análise comportamental. Permite a aquisição e o desenvolvimento de tais habilidades, preparando o professor para desempenhar posteriormente suas funções em sala de aula (KUENZER; MACHADO, 1982).

- Telensino: proposta de aulas para as séries terminais do, então, ensino de $1^{\circ}$ grau, assentada em emissões de televisão, complementadas por materiais 
impressos e pela ação, em sala de aula, do orientador de aprendizagem polivalente.

- Instrução Programada: consiste em dividir o material a ser ensinado em módulos, ou seja, pequenos segmentos logicamente encadeados. $\mathrm{O}$ aprendiz recebe uma instrução, logo em seguida é questionado sobre ela, e mediatamente recebe o retorno. Visa fundamentalmente à memorização de conceitos (SKINNER, 1972).

- Máquinas de Ensinar: programadas com vários exercícios que deveriam ser respondidos pelo aluno. Cada resposta correta era corrigida na mesma hora (reforço imediato) e cada aluno resolvia os módulos (grupo de exercícios) em seu tempo. O professor passa a ser um monitor, tirando dúvidas e explicando apenas o necessário para cada módulo (SKINNER, 1972).

Foi nesse ambiente político e pedagógico que se situou o trabalho docente. $\mathrm{O}$ funcionamento eficiente e eficaz na educação tecnicista implicava na utilização de retroprojetores, na construção infindável de verbos adequados para explicitar os objetivos gerais e específicos das diferentes disciplinas, na explicitação da atividade pedagógica toda clarificada por organogramas, na obrigatoriedade e no controle de uma determinada quantidade de avaliações dadas pelo professor, exemplifica Araújo (2002). A burocratização do planejamento e da ação pedagógica justificava o uso de determinadas técnicas ou de recursos a fim de obter sucesso no ensino. Acreditava-se na aprendizagem significativa do aluno pelo uso das técnicas (ARAÚJO, 2002).

No contexto do Governo Militar, a ineficiência educativa passa a ser combatida com propostas de planejamento educacional, a partir dos estudos dos economistas da educação, tendo em vista o significativo aumento da demanda social, paralelamente à escassez de recursos de toda a natureza e, em resposta ao aumento da demanda, ocorrem a expansão e complexificação dos sistemas de ensino (GHIRALDELLI JÚNIOR, 1987).

Essas proposições eram plenamente justificadas pela própria ideologia do regime militar, expressa pela Escola Superior de Guerra (ESG). O desenvolvimento com segurança exigiu o aumento da produtividade do sistema de ensino. Isso porque a educação era encarada como um instrumento capaz de promover, sem contradição, o desenvolvimento econômico pela qualificação da mão de obra, pela maximização da produção e, ao mesmo tempo, o desenvolvimento da "consciência política", indispensável à manutenção do Estado autoritário, afirma Ghiraldelli Júnior (1987).

A forma de abordar a educação pela racionalização dos aspectos administrativo e pedagógico passou, então, a ser disseminada a partir de vários eventos brasileiros. Um dos principais foram os convênios entre o Ministério da Educação e Cultura e a Agência Norte-Americana para o Desenvolvimento Internacional, acordos MEC/USAID, iniciados em 1964. 
A ótica dos acordos era a mesma declara em tom "científico" pelo ministro do Planejamento do governo, Castello Branco, em 1968, no fórum do Instituto de Pesquisas e Estudos Sociais (Ipes) ${ }^{4}$, uma entidade conservadora que fazia frente ao tipo de posicionamento de esquerda do Instituto Superior de Estudos Brasileiros (Iseb), antes de 1964 (GATTI JÚNIOR, 2010, p. 49).

De acordo com Romanelli (2002), os acordos previam ações planejadoras e organizadoras da educação que implicava treinamento de órgãos e professores. Os acordos MEC-USAID foram "[...] considerados pelo movimento estudantil como sendo contrários à soberania nacional, proibitivos em relação à participação estudantil na definição da política educacional e orientadores da transformação do ensino gratuito em ensino pago" (SANFELICE, 1986, p. 169-170). Outros eventos foram Simpósios Interamericanos de Administração Educacional, em 1968, e o desenvolvimento da teleducação no Brasil, a partir de 1969 (KUENZER; MACHADO, 1982). Em todos os níveis, assistiu-se à reorganização do Ensino Superior e do Ensino de $1^{\circ}$ e $2^{\circ}$ graus que mostraremos a seguir.

A reforma do Ensino Superior, Lei n. 5.540/68, teve como proposta garantir " $[. .$.$] a eficiência, modernização e flexibilidade administrativa da$ universidade brasileira, tendo em vista a formação de recursos humanos de alto nível para o desenvolvimento do país" (BRASIL, 1968, p. 1). Para além da legislação, na reforma, o discurso do especialista tecnocrata, que se imbuia da "verdade absoluta" contida em suas proposições, adequou-se aos regimes autoritários, exigindo para sua efetivação um aparelho de Estado forte, que impedisse a contestação de qualquer grupo que viesse a pôr em dúvida sua pseudoautoridade técnico-científica (FÁVERO, 1991).

Essa reforma instituiu a departamentalização nas universidades que passou a reunir professores-pesquisadores do que seria uma mesma área do conhecimento, diminuindo as reuniões por afinidades teóricas e impondo uma aglomeração de cunho corporativista, afirma Ghiraldelli Júnior (1990). As matrículas por disciplinas, outra alteração da lei, também impediam a interação entre os estudantes e professores dentro de um mesmo curso de nível superior, criando-se uma mentalidade empresarial dentro das escolas.

O curso de pedagogia, sob a regulamentação do Parecer do Conselho Federal de Educação (CFE) n. 252/69, passou a formar especialistas através das habilitações de Magistério das Disciplinas Pedagógicas do Segundo Grau, Orientação Educacional, Supervisão Escolar, Administração e Inspeção

\footnotetext{
${ }^{4}$ Sobre a atuação do projeto educacional do Ipes no contexto do Golpe Militar Brasileiro, consultar GATTI JÚNIOR, D. A Pedagogia Tecnicista no Contexto Brasileiro do Golpe Militar de 1964: o projeto educacional do IPES. Cadernos de História da Educação, Uberlândia, v. 9, n. 1, p. 45-63, jan./jun. 2010.
} 
Escolar, propiciando, assim, a fragmentação do trabalho pedagógico ao dividir a formação do pedagogo em habilitações. Adotou-se, também, o vestibular unificado e classificatório e incentivou a privatização do ensino superior.

Já a Lei n. 5.692/71, que regulava a Reforma do $1^{\circ}$ e $2^{\circ}$ Graus, foi promulgada nos anos de maior repressão do regime e, também, em um dos períodos de maior euforia dos setores médios da população brasileira, o Milagre Econômico $^{5}$. Os professores, suscetíveis à propaganda governamental e encantados pelas marcas fluidas de inovação contidas na lei, transformaram-se em verdadeiros arautos do governo na implantação da lei (GHIRALDELLI JÚNIOR, 2003). De acordo com a nova legislação, os anteriores cursos primários e ciclo ginasial foram agrupados no ensino de $1^{\circ}$ grau para atender crianças e jovens de 7 a 14 anos, ampliando a obrigatoriedade escolar de quatro para oito anos, pontua Nunes (2002).

O $2^{\circ}$ grau, por sua vez, tornou-se integralmente profissionalizante. No entanto, foram enormes as dificuldades financeiras de implantação de laboratórios e de instalação de equipamentos nas escolas públicas para o atendimento da obrigatoriedade da profissionalização cobrada pela lei. Muitas instituições escolares nunca chegaram a disponibilizar as disciplinas profissionalizantes para os estudantes pela falta de habilitação e de laboratórios, gerando uma pressão muito grande para o fim da exigência. Somente com a Lei n. 7.044, que entrou em vigor em 1982, alteraram-se os dispositivos da Lei n. $5.692 / 71$, no que se refere à profissionalização do ensino de $2^{\circ}$ grau.

Essa norma acarretou algumas mudanças na estrutura curricular vigente, liberando as escolas de segundo grau da obrigatoriedade da profissionalização, retornando a ênfase deste curso à formação geral. É obvio que durante esse tempo os colégios particulares souberam desconsiderar toda essa parafernália "profissionalizante" para propiciar o acesso às faculdades e universidades. E as escolas públicas, obrigadas a cumprir a lei, foram descaracterizadas (NUNES, 2002).

\footnotetext{
${ }^{5}$ A partir de 1968, o governo passou a desencadear uma política liberal de crédito. A economia nacional, após vários anos submetida à recessão com o desemprego campeante e com baixa capacidade produtiva, foi facilmente mobilizada. As indústrias concentraram-se na produção de bens de consumo típicos das camadas de renda mais elevadas, camadas estas que aderiram fantasticamente ao consumismo desenfreado, que possibilitou um repentino crescimento econômico. Viveu-se o "milagre econômico". Mas após 1972 o milagre começou a mostrar sua verdadeira face. A baixa qualidade da mão de obra, a criação de um mercado concentrado no consumo dos setores sociais mais ricos, os limites tecnológicos da indústria e as vicissitudes do mercado mundial que acabaram impondo restrições à economia brasileira voltada para a exportação. Enfim, tudo isso compôs um quadro de dificuldades para a economia do país (GHIRALDELLI JÚNIOR, 2003, p. 141).
} 
Kuenzer e Machado (1982) afirmam que em função da introdução das disciplinas Estudos Sociais, Educação Moral e Cívica e Organização Social e Política no Brasil (OSPB) houve a exclusão de disciplinas como a filosofia e a diminuição da carga horária de outras como história e geografia, o que comprometeu a formação dos estudantes.

Finalmente, segundo Ghiraldelli Júnior (2003), não foram colocados recursos humanos e materiais para transformar toda uma rede de ensino nacional em profissionalizante. Por fim, o equívoco maior da lei foi desativar a Escola Normal e transformar o curso de formação de professores das quatro séries iniciais do Ensino Básico em Habilitação para o Magistério.

\section{O lugar das técnicas no processo pedagógico}

Nos anos 80 do século passado, segundo Araújo (2002) e Kuenzer e Machado (1982), vão emergir contundentes críticas ao Tecnicismo Educacional como: a elaboração dos procedimentos e objetivos pelos especialistas da educação; a desconsideração das diferenças de classe entre os estudantes, aliado à crença de que é possível compensar as deficiências; a inversão da avaliação e do próprio processo pedagógico, na medida em que as técnicas determinam os fins e só se ensina comportamentos que possam ser mensuráveis e que estejam previamente previstos no processo e, finalmente, o ocultamento das relações entre educação e sociedade.

As diferenças de classe não tinham relevância, o aluno podia ser recuperado, compensado. É tudo uma questão de usar o procedimento correto e racional: fazer o diagnóstico, levantar o problema, selecionar os meios, desencadear o processo, avaliá-lo e realimentá-lo. As relações entre escola e sociedade ficam ocultas por uma abordagem exclusivamente interna dos problemas da educação. O que se propõe é uma modelização dos alunos pela substituição da pedagogia tradicional pela "nova pedagogia" com seus sistemas de tecnologia sofisticada. A motivação aparece como fundamental para despertar o aluno para o novo modelo de comportamento que deverá ser assimilado consciente ou inconscientemente; para mantê-la os objetivos são fragmentados, taylorizados, possibilitando o avanço eficiente de cada aluno segundo seu ritmo (KUENZER; MACHADO, 1982, p. 50).

Nos termos de Saviani (2010, p. 381), a Pedagogia Tecnicista, ao transpor para a escola "[...] a forma de funcionamento do sistema fabril, perdeu a especificidade da educação, ignorando que a articulação entre escola e o processo produtivo se dá de modo indireto e por meio de complexas mediações". 
Junto a essas críticas e pela assimilação do conhecimento sobre as teorias crítico-reprodutivistas, tornou-se, então, difícil ser tecnicista, afirma Araújo (2002). Os que militavam pedagogicamente, patrocinados por essa posição, entraram em um processo de enclausuramento, dado que se antes era difícil não ser tecnicista, ou simplesmente não era fácil resistir à sua imposição, agora tornara-se difícil sê-lo, como se fosse algo indecoroso. Assim, o Tecnicismo, com suas práticas pedagógicas, deixa de ser um paradigma confiável e, portanto, recomendável à prática docente.

Ao situar a prática social para além da dimensão pedagógica, fica claro que quaisquer técnicas de ensino não têm existência em si, nem racionalidade em si como apregoava o Tecnicismo. A pretensão deste é que, ocorrendo a correta sequenciação dos processos determinados, estariam simplesmente garantidos o ensino e a aprendizagem de qualidade. Nessa perspectiva, a racionalidade do processo pedagógico estaria nos meios, bastariam as estratégias e as táticas bem conduzidas para realizar em plenitude a atividade de ensinar, afirma Araújo (2002).

Isso implica que a racionalidade de tais meios está subordinada aos fins e capazes de dar suporte aos meios, aos instrumentos, à atividade, às funções. A racionalidade de uma ação instrumental (prática) carrega consigo uma racionalidade teórica, onde se encontram os fins, os valores, as crenças que se pretendem atingir ou vivenciar (ARAÚJO, 2002, p. 48).

Além disso, embora possam ser ressaltados os aspectos universais das diferentes técnicas de ensino, isso não significa necessariamente constituí-las neutras ou compreendê-las sob formalismos deslocados da situação históricosocial, afirma Araújo (2002). Essa é sempre o ponto de partida responsável pela gestação das técnicas e dos métodos: Comênio, Herbart, Dewey, Montessori, Decroly, Freinet, Makarenko são apenas alguns exemplos entre outros que possibilitam refletir sobre as interferências histórico-sociais na gestação e formalização dos métodos e das técnicas de ensino. A técnica está ligada ao contexto em que surge, bem como à teoria pedagógica que a ilumina.

Desta forma, toda técnica é tecida e envolvida por determinados ideais educativos. Não é a técnica que define o ideal educativo. As técnicas estão a serviço do processo de ensino, e não o contrário. As técnicas estão destinadas ao professor e ao aluno, e não estes às técnicas. Portanto, é possível usar o datashow sem ser tecnicista. É possível realizar o estudo dirigido sem aquela auréola planificante que o definia. É possível a aula expositiva sem ser tradicional. $\mathrm{O}$ estudo de texto como técnica de ensino implica, embora não necessariamente, estudo do meio, experimentação, pesquisa bibliográfica. O seminário como técnica de ensino implica discussão, debate, trabalho em grupo, estudo dirigido e exposição. 
Compartimentar as dimensões técnica e metodológica, e separá-las do conteúdo e dos outros elementos componentes da prática pedagógica significa embarcar em navios metafísicos. Sobrelevar a dimensão técnica ou atribuir-lhe uma existência em si significa separar o que não pode ser separado (ARAÚJO, 2002).

É importante pontuar a análise conceitual de Freitas (2011), válida para o contexto (neo)tecnicista mais recente, apresentado agora sob a forma de um processo de ensino e aprendizagem centrado nos resultados, onde se propõe a mesma racionalidade técnica dos anos setenta, para assim garantir a eficiência e a produtividade na educação. As políticas educacionais passam a enfatizar o critério da qualidade com base em um fundamento: a utilização intensiva das Tecnologias da Informação e Comunicação (TIC) como estratégia (muito mais sofisticada do que a tecnologia educacional dos anos setenta) de adequação da educação escolar à sociedade da informação (SILVA, 2016).

A padronização e a homogeneidade do processo de ensino e aprendizagem foram instituídas na forma de planejamentos previamente formulados. Isto é, da mesma forma que a concepção do trabalho fabril, a Pedagogia Tecnicista se sustenta nos pressupostos da objetividade e racionalidade buscando minimizar as interferências subjetivas, através da mecanização do processo educativo. Sob essa perspectiva, ao se analisar o ato do conhecimento no paradigma tecnicista, o foco está no objeto a ser conhecido e não no trabalho intelectual do sujeito. Outro aspecto é o reducionismo tecnicista que desconsidera a complexidade do processo pedagógico quando remete as relações na escola, meramente à aplicação de técnicas, afirma Silva (2016).

Para concluir, tomemos as palavras do professor Araújo (2002, p. 54), ao citar o clássico "Professores para quê?", de Gusdorf (1978), para quem a "[...] tarefa presente de uma cultura é precisamente pôr em ordem, uma ordem à escala humana, um mundo precisamente desequilibrado pela proliferação incontrolada das ciências e das técnicas. A tarefa é hoje mais difícil do que jamais foi.". Aliás, a reflexão pedagógica atual é o sinal inegável da crise de consciência da nossa civilização, pois nunca se inquiriu tanto sobre a questão de saber o que é preciso ensinar, a quem e como, diz Araújo (2002). Embora esses escritos datem de 1963, e sejam fruto de reflexão de outro contexto, traduzem a atmosfera que respiramos. Embora a prática docente tornou-se menos vulnerável com as promessas do Tecnicismo, parece um só tempo, tempo de Tecnicismo ainda a nos seduzir. 


\section{Considerações Finais}

O presente capítulo teve o objetivo apresentar as ideias básicas que constituem a pedagogia Tecnicista para compreender o contexto em que essa tendência foi se delineando no ensino brasileiro. O Tecnicismo Educacional foi uma linha de ensino que surgiu no Brasil em meados da década de 1950, mas foi introduzida efetivamente no final dos anos 60 , com predomínio a partir de 1978, que privilegiava excessivamente a tecnologia educacional e transformava educadores e educandos em meros executores e receptores de projetos elaborados de forma autoritária e sem qualquer vínculo com o contexto social a que se destinavam.

A relação entre os modelos de racionalização, típicos do sistema de produção capitalista, serviu de orientação para o Tecnicismo aplicado à educação. O papel da escola articula-se com o sistema produtivo para aperfeiçoamento do sistema capitalista, preocupando-se com a formação de indivíduos para o mercado de trabalho, de acordo com as exigências da sociedade industrial e tecnológica.

A exigência da produtividade do sistema de ensino, por intermédio da racionalização, propôs objetivos de ensino fragmentados. As Leis 5.540/68 (ensino universitário) e 5.692/71 (ensino de $1^{\circ}$ e $2^{\circ}$ graus) são marcos da implantação do modelo tecnicista. Há uma ênfase nos meios que passam a determinar os objetivos. Isto posto, há uma inversão no processo pedagógico, de modo que as técnicas determinam os fins.

Em outros termos, ocorre uma mudança qualitativa na organização do trabalho pedagógico da escola, que passa a ter como base um ensino que busca resultado uniforme, com ênfase em métodos e técnicas de ensino e na valorização da utilização de manuais, livros didáticos, módulos de ensino e recursos audiovisuais. Deste modo, é dada toda atenção em modos instrucionais que possibilitam controle efetivo dos resultados, como: instrução programada, pacotes de ensino, módulos instrucionais etc.

Nesta linha, o professor é apenas um elo de ligação entre a verdade científica e o aluno; o professor é o técnico responsável pela eficiência do ensino. Já o aluno é um ser fragmentado, espectador que está sendo preparado para o mercado de trabalho para "aprender a fazer". Já a função da avaliação ganha ênfase na produtividade do aluno, mensurada a partir de testes objetivos com realização de exercícios programados ocorrendo no final do processo, com a finalidade de constatar se os alunos adquiriram os comportamentos desejados.

Enfim, além de apresentar características autoritárias, a pedagogia Tecnicista pode ser considerada não-dialógica, ou seja, ao aluno cabe assimilar passivamente os conteúdos transmitidos pelo professor. Essa pedagogia difere da progressista que privilegia a formação de cidadãos participativos e 
conscientes da sociedade em que vivem. Em outros termos, o tecnicismo privilegiou as questões do que fazer educativo, partindo de uma dimensão marcadamente técnica.

\section{Referências}

ABBAGNANO, N. Dicionário de Filosofia. 5. ed. São Paulo: Martins Fontes, 2007.

ARAÚJO, J. C. S. Para uma análise das representações sobre técnica de ensino. In: VEIGA, I. P. A. (org.). Técnicas de ensino: por quê não? 13. ed.

Campinas: Papirus, 2002, p. 56-71.

BERTALANFFY, L. V. Teoria Geral dos Sistemas. Petrópolis: Vozes, 1975.

BRASIL. Lei $\mathrm{n}^{\mathbf{0}}$ 5.692, de 11 de agosto de 1971. Fixa Diretrizes e Bases para o ensino de $1^{\circ}$ e $2^{\circ}$ graus, e dá outras providências. Ministério da Educação e Cultura, Brasília/DF [1971]. Disponível em:

http://www.pedagogiaemfoco.pro.br/15692_71.htm. Acesso em: 10 jun. 2014.

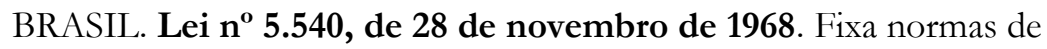
organização e funcionamento do ensino superior e sua articulação com a escola média, e dá outras providências. Ministério da Educação e Cultura, Brasília/DF [1968]. Disponível em: http://www.pedagogiaemfoco.pro.br/15540_68.htm.

Acesso em: 10 jun. 2014.

BRASIL. Lei $\mathbf{n}^{\mathbf{0}} \mathbf{7 . 0 4 4}$, de 18 de outubro de 1982. Altera dispositivos da Lei $\mathrm{n}$. $5.692 / 71$, referentes à profissionalização do ensino de $2^{\circ}$ grau. Ministério da Educação e Cultura, Brasília/DF [1982]. Disponível em:

http://www.pedagogiaemfoco.pro.br/17044_82.htm. Acesso em 10 jun. 2014.

BRASIL. Parecer n ${ }^{\circ}$ 252/69, de abril de 1969. Conselho Federal de Educação. Fixa os mínimos de 7306 conteúdo e duração a serem observados na organização do curso de Pedagogia. In: Documenta no 100. Abr. 1969, p. 101139.

CANDIOTTO, C. Aproximações entre capital humano e qualidade total na educação. Educar em Revista, Curitiba, v. 1, n. 19, p. 199-216, 2002.

FÁVERO, M. de L. de A. Da Universidade “modernizada” à Universidade Disciplinada. São Paulo: Cortez, 1991.

FREITAS, L. C. de. Responsabilização, meritocracia e privatização: conseguiremos escapar ao neotecnicismo? In: Seminário de Educação Brasileira, Centro de Estudos Educação e Sociedade. Campinas: CEDES, 2011, p. 28-36. 
GATTI JÚNIOR, D. A Pedagogia Tecnicista no Contexto Brasileiro do Golpe Militar de 1964: o projeto educacional do IPES. Cadernos de História da Educação, Uberlândia, v. 9, n. 1, p. 45-63, jan./jun. 2010.

GHIRALDELLI JÚNIOR, P. A evolução das ideias pedagógicas no Brasil Republicano. Cadernos de Pesquisa, São Paulo, n. 60, p. 28-37, fev. 1987. GHIRALDELLI JÚNIOR, P. A pedagogia histórico-crítica no contexto das relações entre a educação e os partidos políticos de esquerda na República. PróPosições. Campinas, v. 3, p. 7-36, dez., 1990.

GHIRALDELLI JÚNIOR, P. Filosofia e História da Educação Brasileira. Barueri: Manole, 2003.

GUSDORF, G. Professores para quê? Para uma pedagogia da pedagogia. 4. ed. Lisboa: Moraes, 1978.

KUENZER, A. Z.; MACHADO, L. R. de S. A Pedagogia Tecnicista. In: MELLO, G. N. de. (org.). Escola nova, Tecnicismo e educação compensatória. São Paulo: Loyola, 1982, p. 28-35.

LUCKESI, C. C. Filosofia da Educação. São Paulo: Cortez, 2003.

NUNES, C. Ensino Normal: formação de professores. Rio de Janeiro: DP\&A, 2002.

ROMANELLI, O. de O. História da Educação no Brasil - 1930-1973. 27. ed. Petrópolis: Vozes, 2002.

SANFELICE, J. L. Movimento Estudantil: a UNE na resistência ao golpe de 64. São Paulo: Cortez, 1986.

SAVIANI, D. Escola e Democracia. 32. ed. Campinas: Autores Associados, 1999.

SAVIANI, D. História das Ideias Pedagógicas no Brasil. Campinas: Autores Associados, 2010.

SEVERINO, A. J. Educação, ideologia e contra-ideologia. São Paulo: EPU, 1986.

SILVA, A. V. M. da. A Pedagogia Tecnicista e a organização do sistema de ensino brasileiro. Revista HISTEDBR On-line, Campinas, n. 70, v. 16, p. 197-209, dez. 2016.

SKINNER, B. F. Tecnologia do Ensino. São Paulo: Summus, 1972. 
TAYLOR, Frederick Winslow. Fundamentos da Administração Científica. In: TAYLOR, Frederick Winslow Princípios da Administração Científica. 7. ed. São Paulo: Atlas, 1976. 